\title{
Continuous Heating Dissolution and Continuous Cooling Precipitation Diagrams of a Nickel-Titanium Shape Memory Alloy
}

\author{
Christian Rowolt $^{1} \cdot$ Benjamin Milkereit $^{1,2}$ (D) $\cdot$ Jette Broer $^{1} \cdot$ Armin $_{\text {Springer }^{3}} \cdot$ \\ Olaf Kessler $^{1,2}$
}

Received: 12 October 2021/Revised: 9 November 2021/Accepted: 10 November 2021/Published online: 23 November 2021

(C) The Author(s) 2021

\begin{abstract}
Binary NiTi alloys are the most common shape memory alloys in medical applications, combining good mechanical properties and high biocompatibility. In NiTi alloys, the shape memory effect is caused by the transformation of an austenite phase to a martensite phase and the reverse process. Transformation temperatures are strongly influenced by the exact chemical composition of the NiTi phase and the presence of precipitates in the microstructure induced by thermo-mechanical treatment, especially solution annealing and ageing. Isothermal timetemperature precipitation diagrams can be found in the literature. Cooling is frequently not considered, as water quenching is typically assumed to be sufficient. To the best of our knowledge, continuous heating dissolution (CHD) and continuous cooling precipitation (CCP) diagrams do not exist. Differential scanning calorimetry (DSC) is a common method to analyse the austenite/martensite transformation in shape memory alloys, but it has not yet been used to analyse precipitation processes during continuous temperature changes. We have enabled DSC to analyse dissolution and precipitation processes in situ during heating as well as during cooling from the solution annealing temperature. Results are presented as CHD and
\end{abstract}

Benjamin Milkereit

benjamin.milkereit@uni-rostock.de

1 Chair of Materials Science, Faculty of Mechanical Engineering and Marine Technology, University of Rostock, Albert Einstein-Str. 2, 18059 Rostock, Germany

2 Competence Centre ${ }^{\circ} \mathrm{CALOR}$, Department Life, Light \& Matter, Faculty of Interdisciplinary Research, University of Rostock, Albert-Einstein-Str. 25, 18059 Rostock, Germany

3 Electron Microscopic Centre, University Medical Centre Rostock, Strempelstraße 14, 18057 Rostock, Germany
CCP diagrams, including information from microstructure analysis and the associated changes in the austenite/martensite transformation temperatures.

Keywords NiTi · Differential scanning calorimetry (DSC) - Continuous heating dissolution diagram (CHD) Dissolution · Continuous cooling precipitation diagram (CCP) - Precipitation

\section{Introduction}

NiTi alloys are the most common shape memory alloys in medical applications, combining good mechanical properties and high biocompatibility [1-5]. In binary NiTi alloys, the shape memory effect is characterised by the transformation of austenite (B2-structure) to martensite (B19'structure) and the reverse process [6]. The low-temperature B19' martensitic phase forms during cooling of the hightemperature B2 austenite phase [7]. In the solution-annealed and quenched condition, the transformation takes place in one step from B2 to B19' during subsequent heating or cooling in the temperature range from -100 to $+100{ }^{\circ} \mathrm{C}$. The transformation temperatures are strongly influenced by the exact chemical composition of the NiTi phase and the presence of precipitates induced by thermomechanical treatments, especially solution annealing and ageing. The formation of $\mathrm{Ni}_{4} \mathrm{Ti}_{3}$ precipitates during ageing or dislocations due to thermo-mechanical treatment hinders the formation of $\mathrm{B} 19^{\prime}$. Depending on the size and density as well as the nucleation site density, these precipitates disturb the direct transformation from B2 to B19'. Beyond that, a second martensitic phase called the intermediate Rphase exists [3]. It has been observed that in the solutionannealed, quenched, and aged stage, the transformation 
takes place in two steps in the temperature range from 100 to $+100{ }^{\circ} \mathrm{C}$. The initial transformation is from B2 to R-phase, which transforms to $\mathrm{B} 19^{\prime}$ and the reverse [3, 7, 8]. The precipitation sequence during isothermal ageing treatment in NiTi alloys can be described as follows:

$$
\begin{aligned}
\alpha(\text { supersaturated B2 NiTi }) & \rightarrow \alpha 1+\mathrm{Ni} 4 \mathrm{Ti} 3 \\
& \rightarrow \alpha 2+\mathrm{Ni} 3 \mathrm{Ti} 2 \\
& \rightarrow \alpha 3+\mathrm{Ni} 3 \mathrm{Ti}
\end{aligned}
$$

$\alpha_{1}, \alpha_{2}$, and $\alpha_{3}$ are matrices with different Ni concentrations [11].

Typically, ageing is done below $600{ }^{\circ} \mathrm{C}$ in the twophase region $\mathrm{NiTi}$ and $\mathrm{Ni}_{3} \mathrm{Ti}$ according to the NiTi phase diagram $[10,12]$. During ageing at lower temperatures and shorter ageing times, $\mathrm{Ni}_{4} \mathrm{Ti}_{3}$ appears in the microstructure, while at higher temperatures and longer ageing times, the equilibrium phase $\mathrm{Ni}_{3} \mathrm{Ti}$ will be precipitated. For intermediate temperatures and times, the metastable $\mathrm{Ni}_{3} \mathrm{Ti}_{2}$ forms. Besides, it is known that the precipitation process and resulting transformation temperatures are also dependent on the heating rate to the solution annealing/ageing temperature as well as the cooling rate from the solution annealing/ageing temperature $[8,11,13-16]$. However, currently, no continuous heating dissolution (CHD) and continuous cooling precipitation (CCP) diagrams for $\mathrm{NiTi}$ alloys exist, and only isothermal time-temperature transformation diagrams can be found in the literature $[1,11,17]$.

Differential scanning calorimetry (DSC) is a common method to analyse the austenitic and martensitic transformation in shape memory alloys (see, for example, Refs. $[1,7,9,10])$, but it has not yet been used to analyse the phase transformations according to the precipitation sequence of $\mathrm{Ni}_{3} \mathrm{Ti}$ (Eq. 1). Recently, DSC has successfully been used to establish CHD and CCP diagrams for several alloying systems, like $\mathrm{Al}, \mathrm{Fe}, \mathrm{Mg}$, or $\mathrm{Ni}$ [18-20]. In this work and for the first time, the DSC method was applied to the analysis of dissolution and precipitation kinetics during continuous temperature changes in a binary NiTi alloy.

\section{Materials and Methods}

The investigated alloy was a Ni-rich binary $\mathrm{NiTi}$ shape memory alloy. In the delivered condition, the material was a $\varnothing 6 \mathrm{~mm}$ cylindrical rod with an austenite finish temperature of $-5^{\circ} \mathrm{C} \pm 10 \mathrm{~K}$. The cylindrical rod was formed by means of round forging from a cast block that was manufactured using vacuum induction melting (VIM). The present alloy was delivered with a nominal composition of 50.9 at.\% $\mathrm{Ni}$ and 49.1 at.\% Ti. Before the DSC experiments, all samples were solution annealed $\left(1000{ }^{\circ} \mathrm{C}\right.$ for
$30 \mathrm{~min}$ in the Setaram Labsys Evo DSC, $700{ }^{\circ} \mathrm{C}$ for $30 \mathrm{~min}$ in the Perkin Elmer Pyris Diamond DSC/8500 DSC) and cooled at a rate of $0.1 \mathrm{~K} / \mathrm{s}$ to create a defined initial condition for subsequent experiments. The sample dimensions and resulting sample masses for the three used types of DSC devices are as follows:

Setaram Labsys Evo DSC: $\varnothing 4.9 \mathrm{~mm} \times 11.6 \mathrm{~mm}$, $\approx 1420 \mathrm{mg}$. Setaram Sensys Evo DSC: $\varnothing 5 \mathrm{~mm} \times 14.4 \mathrm{~mm}, \approx 1850 \mathrm{mg}$. Perkin Elmer Pyris Diamond DSC/8500 DSC: $\varnothing 6 \mathrm{~mm} \times 1 \mathrm{~mm}, \approx 180 \mathrm{mg}$.

The applied scan rates were varied over a wide dynamic range, from 0.01 to $5 \mathrm{~K} / \mathrm{s}$ for the heating experiments and from 0.01 to $1 \mathrm{~K} / \mathrm{s}$ for the cooling experiments. Further cooling experiments with 0.001 to $0.03 \mathrm{~K} / \mathrm{s}$ rates were performed for metallographic analysis. The DSC data evaluation for the heating experiments was performed according to Ref. [21] and for the cooling experiments according to Ref. [22]. The experimental setup to perform high-temperature DSC with solution annealing temperatures of $1000{ }^{\circ} \mathrm{C}$ in a heat flux DSC Setaram Labsys EVO is described in Ref. [20]. The technical ceramic Rescor960 with the same geometry as the sample was employed as an appropriate reference material for the baseline measurement. DSC samples were packed in commercial ceramic crucibles. Two sample measurements and one baseline measurement were performed for each parameter setup.

For DSC experiments with temperatures up to $700{ }^{\circ} \mathrm{C}$, the heat flux DSC Setaram Sensys Evo and the power compensated Perkin Elmer Pyris Diamond DSC were used. According to the Ni-Ti phase diagram, a temperature of $700{ }^{\circ} \mathrm{C}$ is sufficiently high to anneal in the single phase field of NiTi [12]. Later on, the DSC experiments will prove this assumption. In this case, the stable $\alpha$-titanium alloy Ti5Al2.5Sn with the same geometry was used as a reference material for maximum temperatures of $700{ }^{\circ} \mathrm{C}$.

To investigate the influence of quench-induced precipitation during cooling from the solution annealing temperature on the martensite transformation, the determination of transformation temperatures from austenite to martensite and the reverse was conducted. Therefore, the standard test method described in ASTM F2004-05 was adapted using a Perkin Elmer Pyris Diamond DSC with sample dimensions of $\emptyset 6 \mathrm{~mm} \times 1 \mathrm{~mm}$. After solution annealing at $700{ }^{\circ} \mathrm{C}$ for $30 \mathrm{~min}$ and cooling with different rates, a common ageing treatment at $500{ }^{\circ} \mathrm{C}$ for $20 \mathrm{~min}$ was performed in a protective nitrogen atmosphere. Afterwards, the temperature range was set from -80 to $+100{ }^{\circ} \mathrm{C}$ at controlled heating and cooling rates of $0.05 \mathrm{~K} / \mathrm{s}$. Fig. 1 shows the applied time/temperature profile for determination of the transformation temperatures. In the case of these experiments, one sample was scanned multiple times in a series of varied cooling rates after solution treatment. This experiment 


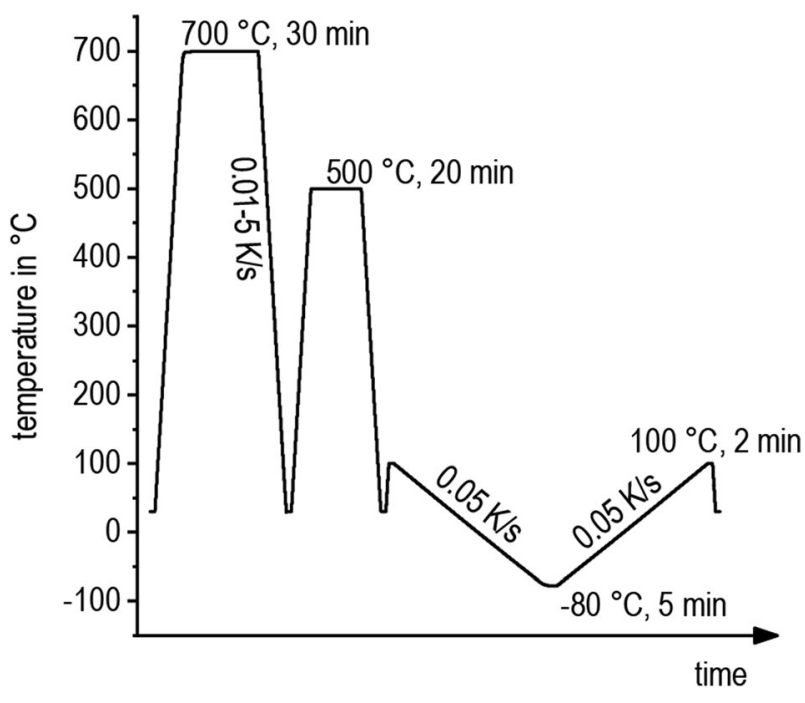

Fig. 1 Time/temperature profile for the determination of transformation temperatures after solution annealing at $700{ }^{\circ} \mathrm{C}$, varying the cooling rate from the solution annealing temperature, and subsequent ageing at $500{ }^{\circ} \mathrm{C}$ for $20 \mathrm{~min}$

series focussed on the determination of variations in the characteristic transformation temperatures. No baseline measurements were done in this special case. This is to allow programming of the series in one experiment-program, and as the raw heat flow was found to be sufficiently precise to allow evaluation of relative variations in the transformation temperatures.

To analyse the changes in the microstructure related to the reactions detected in DSC, optical microscopy (OM) as well as scanning electron microscopy (SEM) and energy dispersive X-ray spectroscopy (EDS) were performed. The heat-treated samples were cold-embedded in epoxy resin and then mechanically ground and polished with water-free lubricants. The final polishing was done with a $0.05 \mu \mathrm{m}$ oxide suspension. The polished samples were rinsed and etched as per following the etching agent: $62.5 \mathrm{ml}$ water $\mathrm{H}_{2} \mathrm{O}, 18.75 \mathrm{~g}$ potassium metabisulfite $\mathrm{K}_{2} \mathrm{~S}_{2} \mathrm{O}_{5}, 12.5 \mathrm{ml}$ hydrochloric acid $\mathrm{HCl}$, and $1.5 \mathrm{~g}$ ammonium hydrogen fluoride $\mathrm{NH}_{4} \mathrm{HF}_{2}$. Microstructural images were acquired by optical microscopy using a LEICA DMI5000 M, Co. Leica Microsystems GmbH, Wetzlar, Germany.

The SEM samples were analysed by a field emission SEM (MERLIN®VP Compact, Co. Zeiss, Oberkochen, Germany) equipped with an EDS detector (XFlash 6/30, Co. Bruker, Berlin, Germany) and analysis software (Quantax400, Co. Bruker, Berlin, Germany). SEM-secondary electron (SEM-SE) images were obtained using a high efficiency Everhart-Thornley-type HE-SE detector at $5 \mathrm{kV}$ acceleration voltage. Representative areas of the samples were analysed and mapped to determine the elemental distribution based on the EDS-spectra data by the QUANTAX ESPRIT Microanalysis software (version 2.0).
The embedded and polished samples were mounted on the SEM carrier with adhesive conductive carbon and aluminium tape (Co. PLANO, Wetzlar, Germany). The acceleration voltage for the EDS analysis was set to $20 \mathrm{kV}$.

Figure 2 shows metallographic images obtained by SEM (polished and unetched) in the initial condition of the NiTi. In the cross section in Fig. $2 a$ and $b$, many small black particles can be observed in the grey matrix. In Fig. 2c and $\mathrm{d}$, images are displayed in the longitudinal direction where aligned particles are evident. EDS proves that the inclusions show a high concentration of titanium and carbon. Furthermore, the nickel content is significantly lower than in the surrounding matrix. The large size (up to a few hundred micrometres) and the high density of those particles correlate with non-metallic inclusions like titanium carbides and oxides, which were also observed in Ref. [23-25]. According to the literature, these inclusions can be traced back to the primary shaping process.

\section{Results and Discussion}

\section{Heating Experiments}

DSC curves during continuous heating using a broad range of heating rates are shown in Fig. 3. For a better understanding, the curves have been offset downwards from the slowest rate on top to the fastest at the bottom. Horizontal dotted lines correspond to the zero level for the curves. Upward deviation of the DSC curve from the zero level indicates domination of endothermal reactions, whilst downward deviations of the DSC curve from the zero level indicate domination of exothermal reactions. One must be aware that the (partly opposing) reactions might superimpose and DSC is just measuring the sum of all heat effects at present. Three different DSC devices were used, as shown by the black, red, and blue curves. In general, there is a good match between the three types of DSC devices used to cover a wide range of heating rates as well as high temperatures.

The DSC-heating curves of $0.01 \mathrm{~K} / \mathrm{s}$ show an exothermal precipitation reaction between 230 and $430{ }^{\circ} \mathrm{C}$ with a distinct peak at $300{ }^{\circ} \mathrm{C}$ (peak a). Additionally, an overlapping precipitation reaction appearing as a shoulder at $350{ }^{\circ} \mathrm{C}$ can be seen (peak b). This holds for rates up to $0.1 \mathrm{~K} / \mathrm{s}$, while the shoulder is no longer seen at higher heating rates. It is believed that in the context of these reactions, parts of the precipitation sequence of $\mathrm{Ni}_{3} \mathrm{Ti}$ (Eq. 1) occur. After crossing the zero level at $430{ }^{\circ} \mathrm{C}$, a subsequent endothermal dissolution reaction with a peak at $580{ }^{\circ} \mathrm{C}$ can be observed (peak C). It can be assumed that previously precipitated particles will be dissolved during this endothermal reaction. It can be seen that the 
Fig. 2 Metallographic images obtained by SEM in the initial condition (polished and unetched). $\mathbf{a}$ and $\mathbf{b}$ cross section, $\mathbf{c}$ and $\mathbf{d}$ longitudinal direction
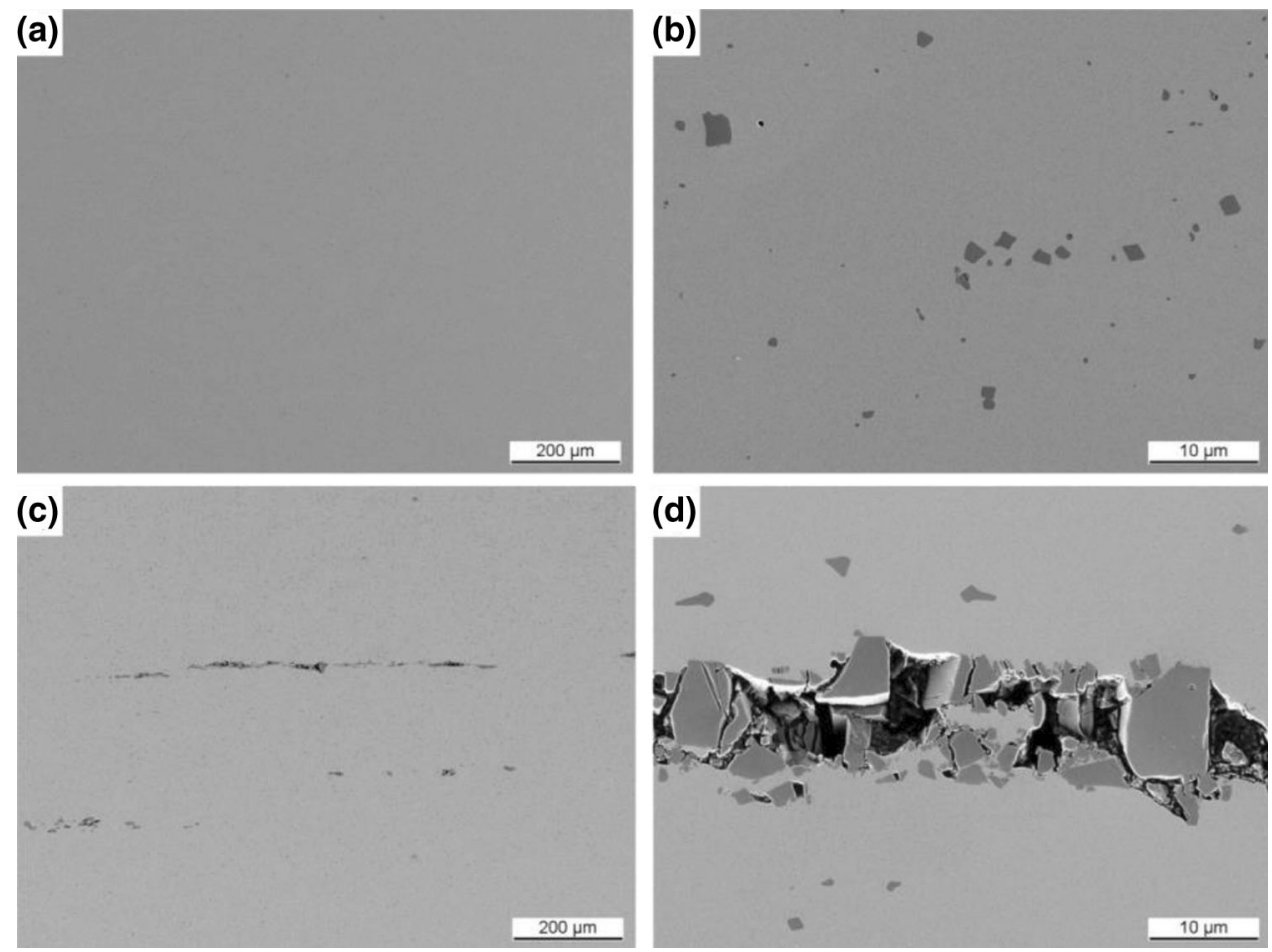

heating at $x \mathrm{~K} / \mathrm{s}$

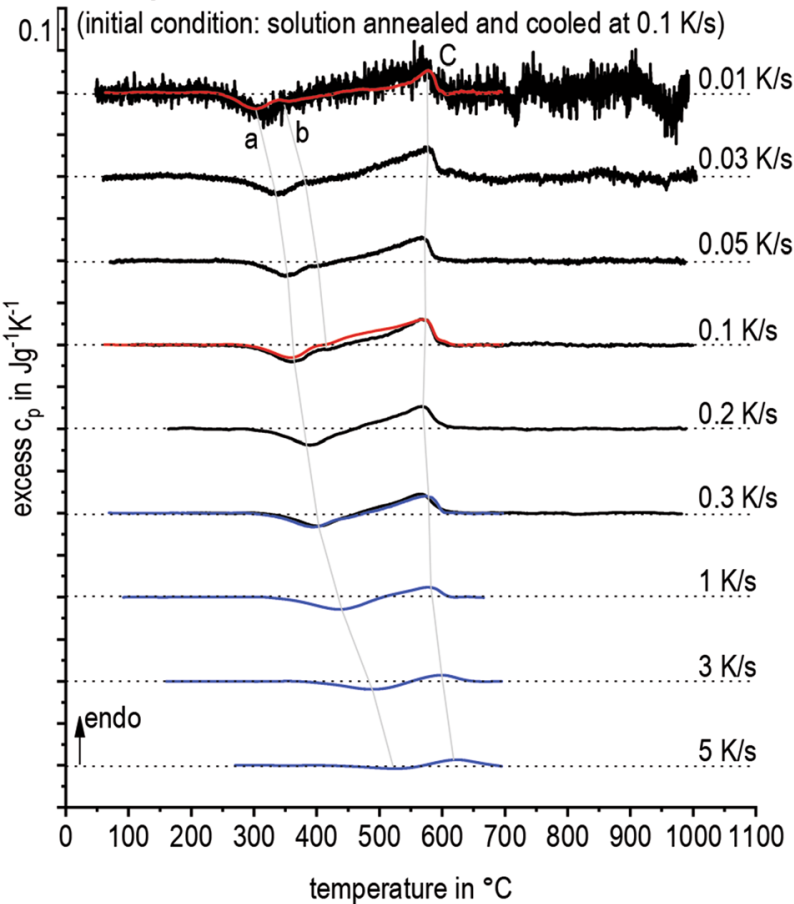

Fig. 3 Selected continuous DSC-heating curves using three different devices: Setaram Labsys Evo (black curves), Setaram Sensys Evo (red curves), and Perkin Elmer Pyris 8500 (blue curves) (Color figure online)

dissolution reaction is finished at $600{ }^{\circ} \mathrm{C}$ and solution annealing above $600{ }^{\circ} \mathrm{C}$ is sufficient to dissolve the alloying elements. A further increase in the temperature results in a horizontal progress of the DSC curve at zero level, indicating a reaction free zone. With increasing heating rate, the precipitation and dissolution reactions and corresponding DSC peaks are significantly shifted to higher temperatures (indicated by the vertical grey spline). In the same order, they are increasingly suppressed. For the fastest investigated heating rate of $5 \mathrm{~K} / \mathrm{s}$, the peak of the exothermal precipitation reaction can be seen at $530{ }^{\circ} \mathrm{C}$, which means a shift of about $230 \mathrm{~K}$ in comparison to heating at $0.01 \mathrm{~K} / \mathrm{s}$. The peak of the endothermal dissolution reaction shifts from $580{ }^{\circ} \mathrm{C}$ at $0.01 \mathrm{~K} / \mathrm{s}$ to $620^{\circ} \mathrm{C}$ at $5 \mathrm{~K} / \mathrm{s}$. The suppression of ongoing reactions during heating can firstly be seen by the disappearance of the shoulder during the exothermal reaction for heating rates higher than $0.1 \mathrm{~K} / \mathrm{s}$ as well as by the reduction of areas under the exoand endothermal peaks.

Figure 4 shows the resulting continuous heating dissolution (CHD) diagram for the specific batch and initial condition of the NiTi alloy 50.9 at.\% $\mathrm{Ni}$ and 49.1 at.\% $\mathrm{Ti}$ are investigated. Therefore, start and end temperatures of characteristic precipitation and dissolution reactions were evaluated and plotted in a temperature/time diagram. From the CHD diagram, during heating to typical ageing temperatures, distinct precipitation and dissolution reactions occur. This means that depending on the considered temperature and heating rate, certain stages in the precipitation sequence of $\mathrm{Ni}_{3} \mathrm{Ti}$ (Eq. 1) can be reached prior to the actual ageing treatment. This aspect must be considered when selecting ageing temperatures and times as premature 


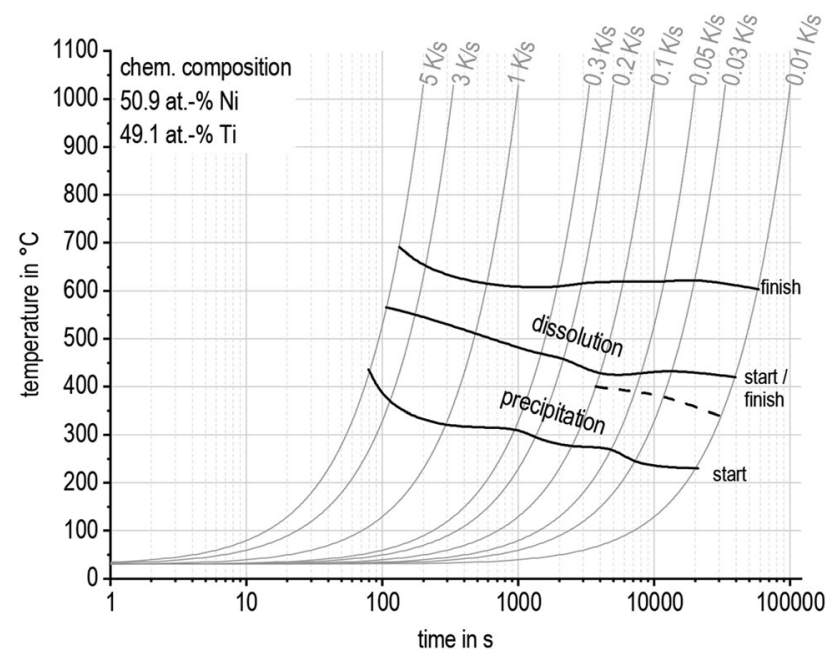

Fig. 4 Continuous heating dissolution (CHD) diagram of 50.9 at. $\% \mathrm{Ni}$ and 49.1 at.\% Ti alloy [initial condition: solution annealed $\left(1000{ }^{\circ} \mathrm{C}\right.$ for $30 \mathrm{~min}$ in Setaram Labsys Evo DSC, $700{ }^{\circ} \mathrm{C}$ for $30 \mathrm{~min}$ in Perkin Elmer Pyris Diamond DSC/8500 DSC) and cooled at $0.1 \mathrm{~K} / \mathrm{s}$ ]

precipitation of nickel rich particles can significantly influence on the transformation temperatures. In consequence different heating rates, especially slower heating rates, can lead to different transformation temperatures under otherwise identical ageing conditions. After running through the different areas of precipitation and dissolution, the heating rate specific solvus temperature is reached. Above this temperature, all major alloying elements are in a solid solution.

\section{Cooling Experiments}

DSC curves from continuous cooling using a broad range of cooling rates are shown in Fig. 5. For a better understanding, the curves have been offset downwards from the slowest rate on top to the fastest at the bottom. Horizontal dotted lines correspond to the zero level for the curves. Upward deviation of the DSC curve from the zero level indicates exothermal reactions. During cooling, only exothermic precipitation is expected; thus, the issue of superimposed reactions is less critical for curve interpretation. Three different DSC devices were used, which are shown by the black, red, and blue curves. Also, during cooling, there is a good match between the three types of DSC devices used to cover a wide range of cooling rates as well as high-temperatures. DSC curves after solution annealing at 700 and $1000{ }^{\circ} \mathrm{C}$ are nearly identical. This agrees with the CHD diagram in Fig. 4.

Considering a cooling rate of $0.01 \mathrm{~K} / \mathrm{s}$, one obvious exothermal precipitation reaction occurs between 420 and $310^{\circ} \mathrm{C}$. With increasing cooling rate, the precipitation reaction is shifted to lower temperatures and gets

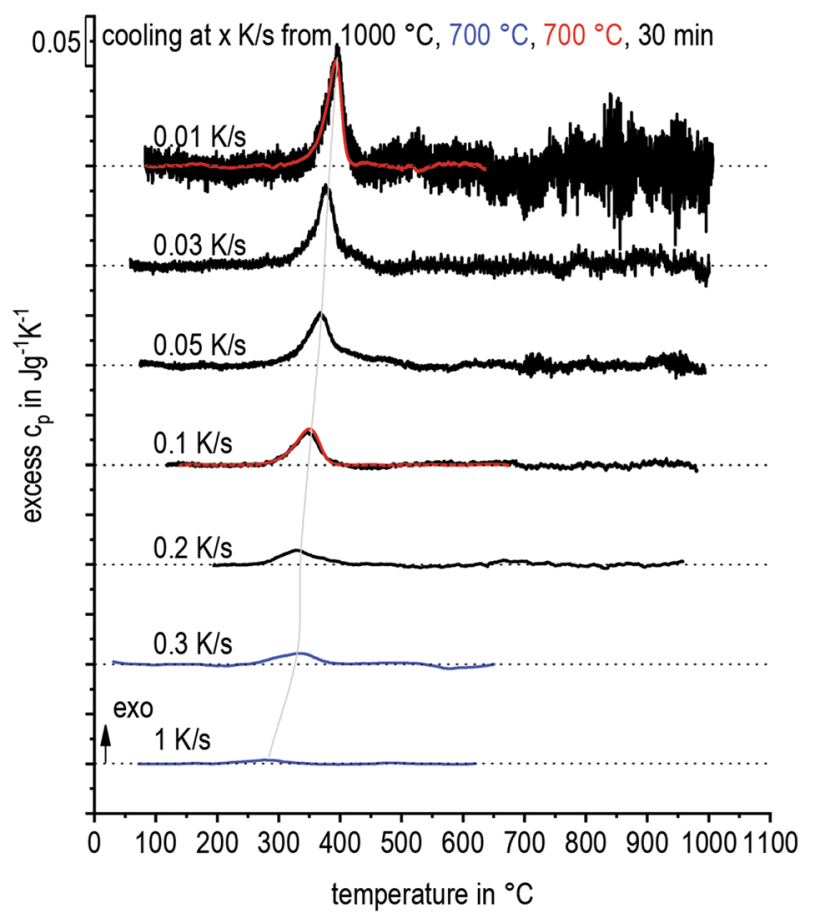

Fig. 5 Selected continuous DSC-cooling curves using three different devices: Setaram Labsys Evo DSC (black curves), Setaram Sensys Evo DSC (red curves), and Perkin Elmer Pyris Diamond DSC (blue curves) (Color figure online)

increasingly suppressed. The peak temperature for $0.01 \mathrm{~K} / \mathrm{s}$ is $395{ }^{\circ} \mathrm{C}$, while it is shifted to $275{ }^{\circ} \mathrm{C}$ at $1 \mathrm{~K} / \mathrm{s}$. However, though the DSC curve of $0.01 \mathrm{~K} / \mathrm{s}$ is quite noisy, another weak, preceding precipitation peak might be present at $520{ }^{\circ} \mathrm{C}$. This assumption is supported by the shoulder seen on the high-temperature side of the subsequent exothermic peak at $0.03 \mathrm{~K} / \mathrm{s}$ and $0.05 \mathrm{~K} / \mathrm{s}$. It can be assumed that this reaction at higher temperatures would be even more pronounced at slower cooling as considered here.

Figure 6 shows the reduction of the total specific precipitation enthalpy with increasing cooling rate. The specific precipitation enthalpy can be calculated by integrating the peak area. In this case, the highest specific precipitation enthalpy is $3.6 \mathrm{~J} / \mathrm{g}$ for the slowest cooling rate of $0.01 \mathrm{~K} / \mathrm{s}$. This value is nearly constant for the next two faster cooling rates. For $0.1 \mathrm{~K} / \mathrm{s}$, the specific precipitation enthalpy drops down to $1.7 \mathrm{~J} / \mathrm{g}$ and decreases further with the increase in the cooling rate. For the highest investigated cooling rate of $1 \mathrm{~K} / \mathrm{s}$, a precipitation enthalpy of just $0.3 \mathrm{~J} /$ $\mathrm{g}$ remains, which is already close to the detection limit of DSC [18, 22]. From this, it can be concluded that the critical cooling rate to completely suppress quench-induced precipitation is just slightly higher than $1 \mathrm{~K} / \mathrm{s}$ (considering a logarithmic cooling rate increment).

The start and end temperatures of the precipitation reaction during cooling from $1000{ }^{\circ} \mathrm{C}$, respectively, to $700{ }^{\circ} \mathrm{C}$ for $30 \mathrm{~min}$ were evaluated. The corresponding 


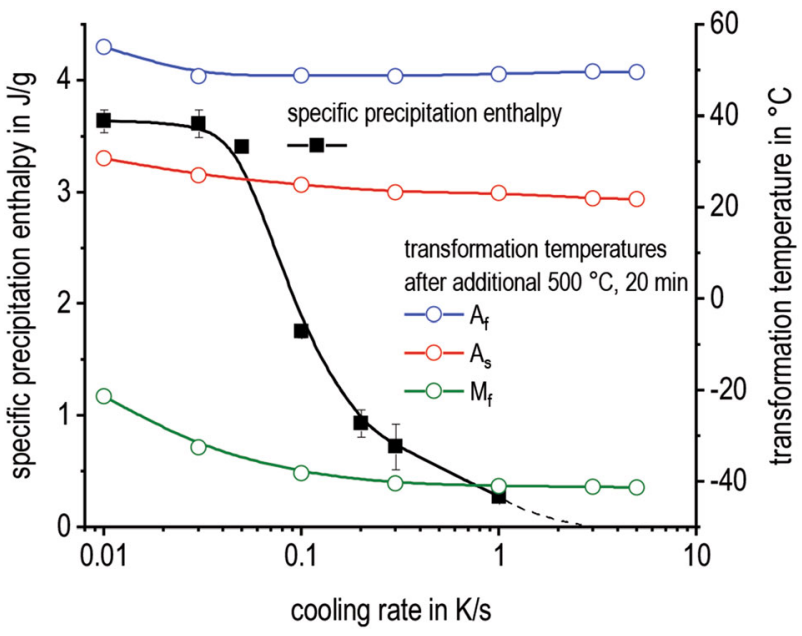

Fig. 6 Specific precipitation enthalpy and transformation temperatures after additional ageing at $500{ }^{\circ} \mathrm{C}$ for $20 \mathrm{~min}$ as a function of cooling rate (Color figure online)

time-temperature data points are plotted in Fig. 7 showing the CCP diagram for the specific batch of the NiTi alloy 50.9 at. $\% \mathrm{Ni}$ and 49.1 at.\% $\mathrm{Ti}$. The two fastest cooling rates were performed starting from a temperature of $700{ }^{\circ} \mathrm{C}$; nevertheless, these two were integrated into the same diagram. The critical cooling rate is estimated to be $3 \mathrm{~K} / \mathrm{s}$, as the specific precipitation enthalpy for $1 \mathrm{~K} / \mathrm{s}$ is almost zero (see Fig. 6). The dashed line proposes the extrapolated start and end temperature for quench-induced precipitation limited by the critical cooling rate at $3 \mathrm{~K} / \mathrm{s}$.

It can be assumed that quench-induced precipitation of phases like $\mathrm{Ni}_{4} \mathrm{Ti}_{3}, \mathrm{Ni}_{3} \mathrm{Ti}_{2}$, or $\mathrm{Ni}_{3} \mathrm{Ti}$ from the precipitation sequence towards $\mathrm{Ni}_{3} \mathrm{Ti}$ (Eq. 1) is observed here. As only one clear exothermal precipitation peak occurs at a cooling rate of $0.01 \mathrm{~K} / \mathrm{s}$, it is expected that slower cooling would

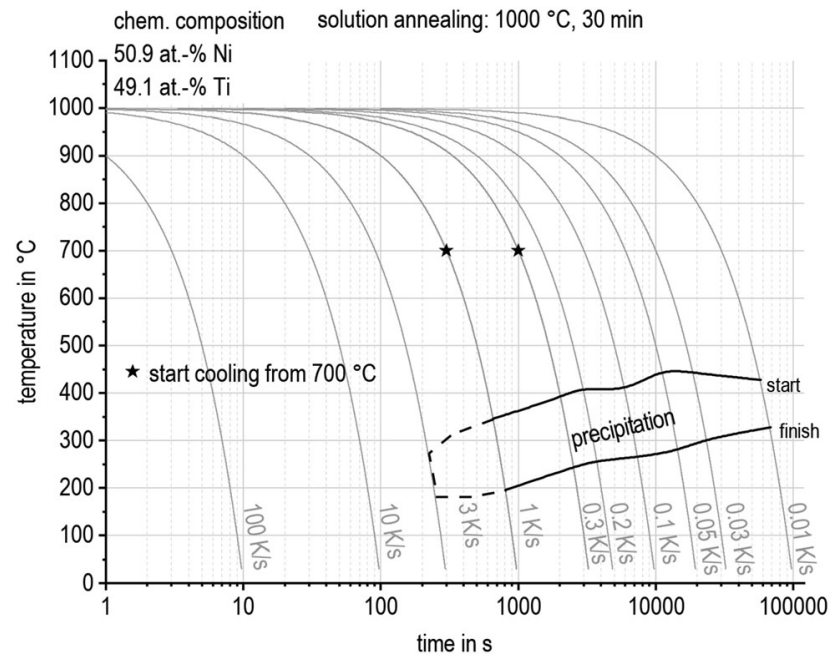

Fig. 7 Continuous cooling precipitation (CCP) diagram of 50.9 at.\% $\mathrm{Ni}$ and 49.1 at.\% $\mathrm{Ti}$ alloy result in multiple overlapping precipitation peaks regarding the precipitation sequence towards $\mathrm{Ni}_{3} \mathrm{Ti}$. This behaviour is well known from other alloying systems, for example, on the basis of $\mathrm{Al}, \mathrm{Fe}$, or $\mathrm{Mg}[18,19]$.

\section{Transformation Behaviour after Cooling with Different Rates}

The influence of the applied cooling rate variation $(0.01-5 \mathrm{~K} / \mathrm{s})$ from the solution annealing temperature on the transformation behaviour between -80 and $+100{ }^{\circ} \mathrm{C}$ after additional ageing is shown in Fig. 8. The cooling step including the endothermal transformation from the hightemperature austenite (B2) phase to the low-temperature martensite $\left(\mathrm{B} 19^{\prime}\right)$ phase is shown in Fig. 8a. During cooling of the sample previously cooled at $0.01 \mathrm{~K} / \mathrm{s}$ from the solution annealing temperature, at least three distinct peaks can be found. During those peaks, a sequence of transformations occurs depending on the specific ratio of $\mathrm{Ni} / \mathrm{Ti}$ and the size, amount, and location of precipitates and dislocations [7-9]. It can be seen from the diagram that faster cooling results in a slight shift of the transformation peak 1 to higher temperatures and the disappearance of the transformation peak 2 for cooling rates higher than $0.3 \mathrm{~K} / \mathrm{s}$. In addition, the transformation peak 3 significantly shifts to lower temperatures with increasing cooling rate from $18{ }^{\circ} \mathrm{C}$ at $0.01 \mathrm{~K} / \mathrm{s}$ to $-38{ }^{\circ} \mathrm{C}$ at $3 \mathrm{~K} / \mathrm{s}$. Comparing the three fastest investigated cooling rates $(1-5 \mathrm{~K} / \mathrm{s})$, no differences can be recognised for the transformation behaviour from austenite to martensite. This agrees with the finding that the critical cooling rate is just slightly higher than $1 \mathrm{~K} / \mathrm{s}$ (Fig. 7).

In Fig. 8b, the subsequent heating from -80 to + $100{ }^{\circ} \mathrm{C}$ is shown. During heating of the low-temperature martensite $\left(\mathrm{B} 19^{\prime}\right)$ phase, two distinct exothermal transformation peaks can be seen, resulting in the formation of the high-temperature austenite (B2) phase. Peak 4 dominates the transformation during heating. The transformation peak 5 only shows up as a shoulder at transformation peak 4. At the temperature at which the overall reaction expires and adopts the course of the imaginary baseline, the transformation is complete and the austenite finish temperature $A_{f}$ has been determined. $A_{f}$ has been evaluated and summarised in Fig. 6. For a prior cooling rate of $0.01 \mathrm{~K} / \mathrm{s}$ from the solution annealing temperature and additional ageing, the $A_{\mathrm{f}}$ temperature is determined to be $55.1{ }^{\circ} \mathrm{C}$. For the next faster cooling of $0.03 \mathrm{~K} / \mathrm{s}$, the $\mathrm{A}_{\mathrm{f}}$ temperature drops to $48.6^{\circ} \mathrm{C}$, staying nearly constant for further increases in the cooling rate. Although the $A_{f}$ temperature is nearly the same, the transformation behaviour differs. The shoulder from peak 5 gets increasingly suppressed and shifted to lower temperatures. 

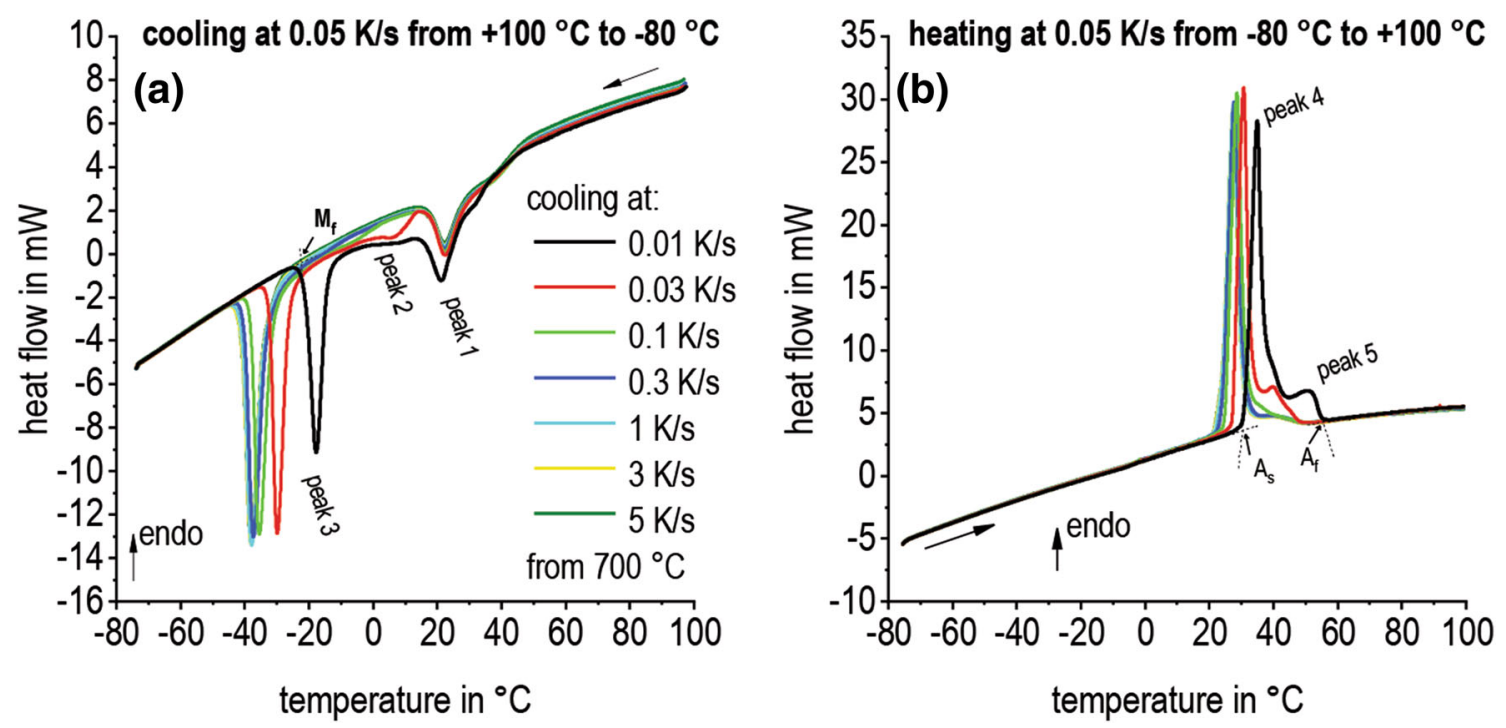

Fig. 8 Influence of the variation of cooling rate from the solution annealing temperature $700{ }^{\circ} \mathrm{C}$ for 30 min on the transformation behaviour after additional ageing at $500{ }^{\circ} \mathrm{C}$ for 20 min during slow cooling (a) and heating (b) between $-80{ }^{\circ} \mathrm{C}$ and $+100{ }^{\circ} \mathrm{C}$ (Color figure online)

In the same manner, we have evaluated the martensite finish $\mathrm{M}_{\mathrm{f}}$ and austenite start $\mathrm{A}_{\mathrm{s}}$ temperatures (Fig. 8). Increasing transformation temperatures $\mathrm{M}_{\mathrm{f}}, \mathrm{A}_{\mathrm{s}}$, and $\mathrm{A}_{\mathrm{f}}$ with a lower cooling rate (Fig. 6) can be explained by the preceding precipitation from the solid solution during cooling. Transformation temperatures rise with decreasing Ni content of the NiTi phase $[6,26]$, and the Ni content itself is reduced by the precipitation sequence (Eq. 1). Thus, stronger precipitation during cooling causes increasing austenite/martensite transformation temperatures.

\section{Microstructures after Cooling with Different Rates}

The metallographic images from optical microscopy of the investigated NiTi alloy are shown in Fig. 9. These samples were continuously cooled from $700{ }^{\circ} \mathrm{C}$ for $30 \mathrm{~min}$ to room
Fig. 9 Microstructure development of NiTi after varying the cooling rate from $700{ }^{\circ} \mathrm{C}$ for $30 \mathrm{~min}$ in an etched condition
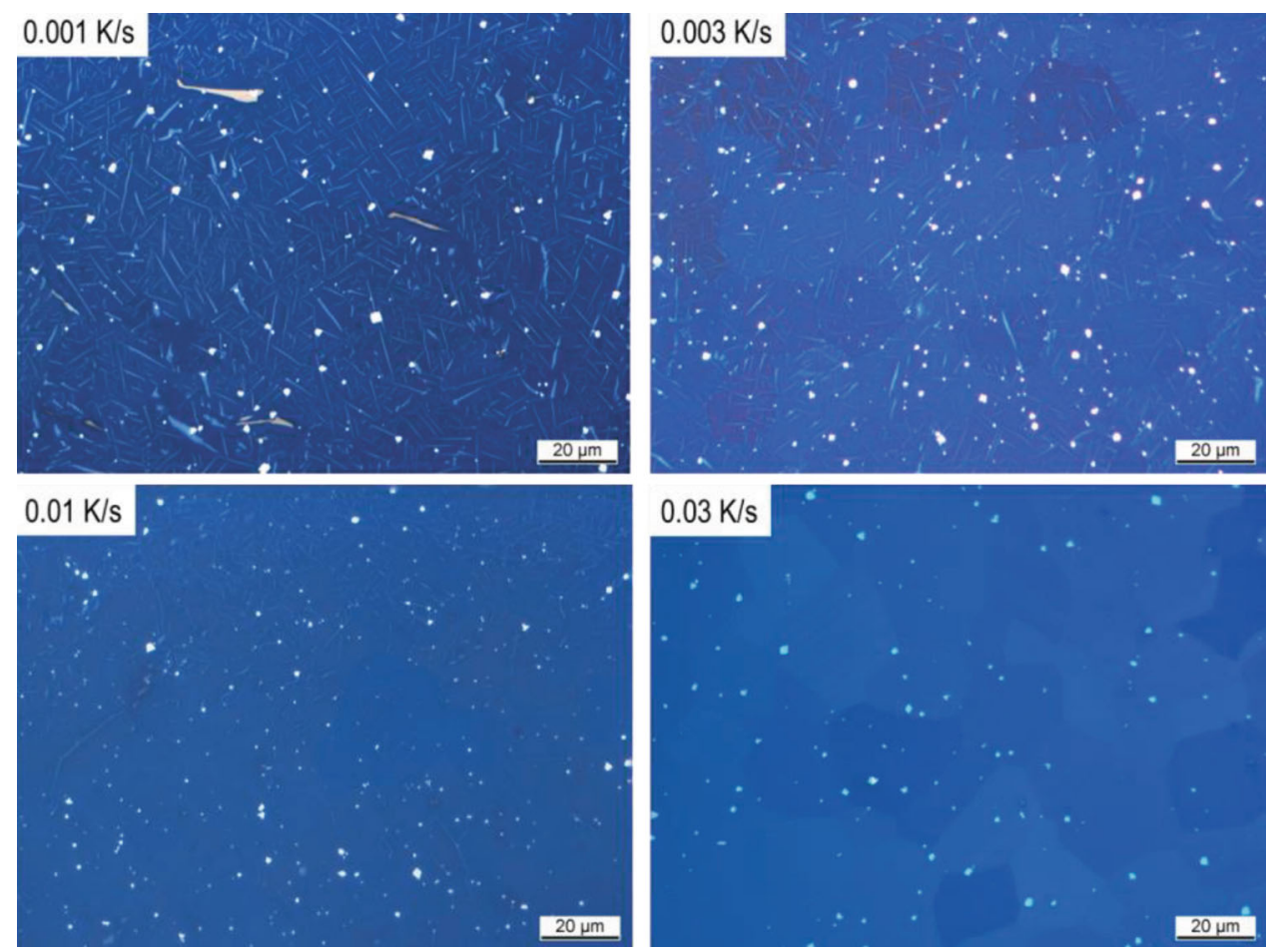
temperature with varying cooling rates from 0.001 to $0.03 \mathrm{~K} / \mathrm{s}$ to promote quench-induced precipitation. No ageing treatment was added. In this state, transformation from austenite to martensite starts significantly below room temperature, i.e. the analysed microstructure consists mainly of austenite. Etching reveals the austenite grains.

Beside the austenitic matrix, obviously a high density of bright polygonal low aspect ratio particles of a few micrometres in diameter exists randomly distributed on all of the images. The size of a few micrometres and the distribution of those particles correlate with non-metallic inclusions like titanium carbides and oxides, which have also been observed in Fig. 2 as well as by [23-25]. Hence, these particles appear independent of the cooling rate.

After the slowest investigated cooling rate of $0.001 \mathrm{~K} / \mathrm{s}$, at least two types of quench-induced precipitates are observed. One type appears as elongated, bright-grey precipitates without a specific shape and orientation and a length of about $20 \mu \mathrm{m}$. It seems that around these particles, precipitate-free zones can be seen. That is, a large proportion of the alloying elements have diffused into these large precipitates. At higher cooling rates, these precipitates are no longer visible, i.e. their formation during cooling is suppressed. As a second type, many blue coloured needle-shaped precipitates can be seen at $0.001 \mathrm{~K} / \mathrm{s}$, ranging in length from up to $20 \mu \mathrm{m}$ down to a few $\mu \mathrm{m}$. With a thickness of only a few hundreds of $\mathrm{nm}$, they exhibit a high aspect ratio. These particles appear in distinct orientations. Since the material under study is a binary alloy of $\mathrm{Ni}$ and $\mathrm{Ti}$, these precipitates are assumed to come from different stages of the precipitation sequence $\mathrm{Ni}_{3} \mathrm{Ti}$ (Eq. 1). However, within the scope of this work, we need to keep the open question of which exact phases are precipitated. Certainly, with increasing cooling rate, these needles become smaller and less in number. After cooling at $0.03 \mathrm{~K} / \mathrm{s}$, no quench-induced precipitates can be seen using optical microscopy. As the DSC-signal clearly indicates an exothermal precipitation reaction during cooling at this rate (Fig. 5), further particles are probably formed at the nanoscale, which need further analysis by transmission electron microscopy (TEM) in the future.

\section{Conclusion}

In this work, the successful application of a sophisticated, systematic differential scanning calorimetry (DSC) in situ analysis of dissolution and precipitation processes during continuous heating and cooling of a Ni-rich binary NiTi shape memory alloy has been shown for the first time. From the systematic DSC analysis combined with optical metallography, we conclude the following:
- Quench-induced precipitation during cooling from the solution annealing temperature was detected by DSC and confirmed by microstructural analysis. The size and number of precipitates decrease with increasing cooling rate.

- A critical cooling rate for quenching from the solution annealing temperature of about $3 \mathrm{~K} / \mathrm{s}$ has been determined.

- The impact of existing (quench-induced) precipitates on the transformation temperatures has systematically been analysed.

- Pre-existing precipitates, i.e. nickel rich particles, can significantly influence on the transformation temperatures. In consequence, different heating rates, especially slower ones, can lead to different transformation temperatures under otherwise identical ageing conditions.

- It can be further concluded that quench-induced precipitation (QIP) also strongly influences the transformation behaviour of austenite to martensite and the reverse. Specifically, with increasing suppression of QIP, the martensite to austenite transformation temperature decreases. E.g. after cooling at various rates from solution treatment and additional ageing $\left(500{ }^{\circ} \mathrm{C}\right.$ $20 \mathrm{~min}$ ), the martensite finish temperature during cooling at $0.05 \mathrm{~K} / \mathrm{s}$ from $100{ }^{\circ} \mathrm{C}$ shifts from $-21^{\circ} \mathrm{C}$ (preceding cooling at $0.01 \mathrm{~K} / \mathrm{s}$ ) to about $-41{ }^{\circ} \mathrm{C}$ after a preceding cooling at $5 \mathrm{~K} / \mathrm{s}$. A continuous heating dissolution (CHD) and a continuous cooling precipitation (CCP) diagram for NiTi have been established. These diagram can be used for the selection of heating and cooling rates in processing NiTi components.

- Future work needs to analyse the nature of quenchinduced precipitation on the micro and nanoscale.

Acknowledgements Financial support by the German Federal Ministry of Education and Research (BMBF) within the project RESPONSE "Partnership for Innovation in Implant Technology" (Grant Number FKZ 03ZZ0928D) is gratefully acknowledged.

Author Contributions CR, BM, and OK designed the experiments. $\mathrm{CR}$ performed and evaluated the experiments. $\mathrm{CR}$ wrote the manuscript. JB and AS performed the SEM analysis. All authors joined the discussion and approved the final version of the paper.

Funding Open Access funding enabled and organized by Projekt DEAL.

\section{Declarations}

Conflict of interest The authors declare that they have no conflict of interest.

Open Access This article is licensed under a Creative Commons Attribution 4.0 International License, which permits use, sharing, adaptation, distribution and reproduction in any medium or format, as 
long as you give appropriate credit to the original author(s) and the source, provide a link to the Creative Commons licence, and indicate if changes were made. The images or other third party material in this article are included in the article's Creative Commons licence, unless indicated otherwise in a credit line to the material. If material is not included in the article's Creative Commons licence and your intended use is not permitted by statutory regulation or exceeds the permitted use, you will need to obtain permission directly from the copyright holder. To view a copy of this licence, visit http://creativecommons. org/licenses/by/4.0/.

\section{References}

1. Pelton AR, Dicello J, Miyazaki S (2000) Optimisation of processing and properties of medical grade Nitinol wire. Minim Invasive Ther Allied Technol 9:107-118. https://doi.org/10.3109/ 13645700009063057

2. Duerig T, Pelton A, Stöckel D (1999) An overview of nitinol medical applications. Mater Sci Eng A 273-275:149-160. https:// doi.org/10.1016/S0921-5093(99)00294-4

3. Otsuka K, Ren X (2005) Physical metallurgy of Ti-Ni-based shape memory alloys. Prog Mater Sci 50:511-678. https://doi. org/10.1016/j.pmatsci.2004.10.001

4. Pelton AR, Russell SM, DiCello J (2003) The physical metallurgy of nitinol for medical applications. JOM 55:33-37. https:// doi.org/10.1007/s11837-003-0243-3

5. Mohd Jani J, Leary M, Subic A et al (2014) A review of shape memory alloy research, applications and opportunities. Mater Des 1980-2015(56):1078-1113. https://doi.org/10.1016/j.matdes. 2013.11.084

6. Frenzel J, George EP, Dlouhy A et al (2010) Influence of Ni on martensitic phase transformations in NiTi shape memory alloys. Acta Mater 58:3444-3458. https://doi.org/10.1016/j.actamat. 2010.02.019

7. Carroll MC, Somsen C, Eggeler G (2004) Multiple-step martensitic transformations in Ni-rich NiTi shape memory alloys. Scripta Mater 50:187-192. https://doi.org/10.1016/j.scriptamat. 2003.09.020

8. Karaca HE, Kaya I, Tobe H et al (2013) Shape memory behavior of high strength Ni54Ti46 alloys. Mater Sci Eng A 580:66-70. https://doi.org/10.1016/j.msea.2013.04.102

9. Fan G, Chen W, Yang S et al (2004) Origin of abnormal multistage martensitic transformation behavior in aged Ni-rich Ti-Ni shape memory alloys. Acta Mater 52:4351-4362. https://doi.org/ 10.1016/j.actamat.2004.06.002

10. Khalil Allafi J, Ren X, Eggeler G (2002) The mechanism of multistage martensitic transformations in aged Ni-rich NiTi shape memory alloys. Acta Mater 50:793-803. https://doi.org/10.1016/ S1359-6454(01)00385-8

11. Nishida M, Wayman CM, Honma T (1986) Precipitation processes in near-equiatomic TiNi shape memory alloys. Metall Mater Trans A 17:1505-1515. https://doi.org/10.1007/ BF02650086

12. Tedenac J-C, Velikanova T, Turchanin M et al. Assessed phase diagram of the Ni-Ti system: datasheet from MSI Eureka in Springer Materials. Accessed https://materials.springer.com/msi/ phase-diagram/docs/sm_msi_r_20_010245_01_full_LnkDia0

13. Nurveren K, Akdoğan A, Huang WM (2008) Evolution of transformation characteristics with heating/cooling rate in $\mathrm{NiTi}$ shape memory alloys. J Mater Process Technol 196:129-134. https://doi.org/10.1016/j.jmatprotec.2007.05.015

14. Zhang $Y$, Jiang $S$, Zhao $Y$ et al (2012) Influence of cooling rate on phase transformation and microstructure of Ti-50.9\% Ni shape memory alloy. Trans Nonferr Metal Soc China 22:2685-2690. https://doi.org/10.1016/S1003-6326(11)61518-5

15. Motemani Y, Nili-Ahmadabadi M, Tan MJ et al (2009) Effect of cooling rate on the phase transformation behavior and mechanical properties of Ni-rich NiTi shape memory alloy. J Alloys Compd 469:164-168. https://doi.org/10.1016/j.jallcom.2008.01.153

16. Coan S, Shamimi A, Duerig TW (2017) Effect of cooling rates on the transformation behavior and mechanical properties of a NiRich NiTi alloy. Shap Mem Superelast 3:315-321. https://doi. org/10.1007/s40830-017-0128-x

17. Adharapurapu RR, Jiang F, Vecchio KS (2010) ageing effects on hardness and dynamic compressive behavior of Ti-55Ni (at.\%) alloy. Mater Sci Eng A 527:1665-1676. https://doi.org/10.1016/j. msea.2009.10.069

18. Milkereit B, Starink MJ, Rometsch PA et al (2019) Review of the quench sensitivity of aluminium alloys: analysis of the kinetics and nature of quench-induced precipitation. Materials 12:1-92. https://doi.org/10.3390/ma12244083

19. Rowolt C, Milkereit B, Springer A et al (2020) Dissolution and precipitation of copper-rich phases during heating and cooling of precipitation hardening steel $\mathrm{X} 5 \mathrm{CrNiCuNb} 16-4$ (17-4 $\mathrm{PH})$. J Mater Sci 55:13244-13257. https://doi.org/10.1007/s10853020-04880-4

20. Rowolt C, Milkereit B, Andreazza P et al (2019) Quantitative high temperature calorimetry on precipitation in steel and nickel alloys. Thermochim Acta 677:169-179. https://doi.org/10.1016/j. tca.2019.01.026

21. Osten J, Milkereit B, Schick C et al (2015) Dissolution and precipitation behaviour during continuous heating of $\mathrm{Al}-\mathrm{Mg}-\mathrm{Si}$ alloys in a wide range of heating rates. Mater 8:2830-2848. https://doi.org/10.3390/ma8052830

22. Milkereit B, Kessler O, Schick C (2009) Recording of continuous cooling precipitation diagrams of aluminium alloys. Thermochim Acta 492:73-78. https://doi.org/10.1016/j.tca.2009.01.027

23. Coda A, Cadelli A, Zanella M et al (2018) Straightforward downsizing of inclusions in NiTi alloys: a new generation of SMA wires with outstanding fatigue life. Shap Mem Superelast 4:41-47. https://doi.org/10.1007/s40830-018-0159-y

24. Robertson SW, Launey M, Shelley O et al (2015) A statistical approach to understand the role of inclusions on the fatigue resistance of superelastic Nitinol wire and tubing. J Mech Behav Biomed 51:119-131. https://doi.org/10.1016/j.jmbbm.2015.07. 003

25. Coda A, Zilio S, Norwich D et al (2012) Characterization of inclusions in VIM/VAR NiTi alloys. J Mater Eng Perform 21:2572-2577. https://doi.org/10.1007/s11665-012-0366-1

26. Khalil-Allafi J, Dlouhy A, Eggeler G (2002) Ni4Ti3-precipitation during ageing of NiTi shape memory alloys and its influence on martensitic phase transformations. Acta Mater 50:4255-4274. https://doi.org/10.1016/S1359-6454(02)00257-4

Publisher's Note Springer Nature remains neutral with regard to jurisdictional claims in published maps and institutional affiliations. 